\title{
O MUSEU FAZENDO EXTENSÃO UNIVERSITÁRIA: UMA PARCERIA ENTRE A INFÂNCIA, CULTURA E MEMÓRIA DE ZILDA ARNS NEUMANN
}

\author{
Edina Regina Baumer ${ }^{1}$, Alice da Silva Meis ${ }^{2}$, Sheila de Souza Brigido ${ }^{3}$
}

\begin{abstract}
RESUMO
O presente artigo tem por objetivo descrever uma experiência de extensão universitária, promovida pelo Museu da Infância da UNESC, que consistiu na realização de uma parceria com a Associação de Amigos da Pastoral da Criança, com o intuito de homenagear a Dra. Zilda Arns, natural de Forquilhinha-SC e reconhecida internacionalmente por seus trabalhos em favor das crianças. A coordenação do Museu da Infância se propôs a elaborar o projeto que definiu como objetivo geral estabelecer a parceria para a organização de uma exposição permanente na Casa Mãe Helena, naquele município. Enquanto o projeto tramitava nos diversos âmbitos necessários para sua oficialização na universidade, duas etapas dessa exposição foram realizadas, registrando em seu livro de assinaturas a presença de 381 visitantes. Os objetos selecionados do acervo do Museu da Infância foram dois bilboques de 1990, uma mesa com cadeiras e um trem de madeira, em miniatura, um carrinho de madeira, um cavalinho de pau, pula-corda, cinco marias, boneca alemã de 1895, objetos relacionados com a ditadura militar e períodos de guerra, como os livros alemães, disco de vinil e um cavalo; dois cestos indígenas, dois chocalhos, arco e flecha, sopro com duas flechas, livro, colar e escultura de animais silvestres; bonecas 'abayomis', boneca de pano, livro e uma boneca negra de 1940. Esses objetos do acervo dialogaram proposicionalmente com as dez aquarelas digitais, tamanho A1, do artista Fabiano Vianna, de Curitiba, e com uma série de fotografias que registram a Dra. Zilda Arns Neumann em ações da Pastoral da Criança.

Palavras-chave: Extensão Universitária; Museu da Infância; Parceria; Zilda Arns.
\end{abstract}

\section{RESUMEN}

Este artículo tiene como objetivo describir una extensión universitaria de la experiencia, promovido por el Museo de la Infancia de la UNESC, que consistía en una alianza con la Asociación de Amigos de la Pastoral, con el fin de cumplir con la Dra. Zilda Arns, natural de Forquilhinha -SC y reconocido internacionalmente por su trabajo en favor de los niños. Coordinación del Museo de la Infancia propone diseñar el proyecto que define el objetivo general de establecer una asociación para la organización de una exposición permanente en la Casa Madre de Helena, en ese municipio. Si bien el proyecto que se estaba desarrollando en los diversos campos necesarios para su reconocimiento oficial en la universidad, se llevaron a cabo dos etapas de esta exposición, grabando en sus firmas de libros, la presencia de 381 invitados. Los objetos seleccionados de la colección del Museo de la niñez eran dos bilboques 1990, una mesa con sillas y un tren de madera, miniatura, soporte de madera uno, el caballo de batalla, saltar-cuerda, cinco Marias, muñeca alemana de 1895 objetos relacionados con la dictadura militar y los períodos de guerra, como los libros alemanes, discos de vinilo y un caballo; dos cestas indias, dos sonajeros, tiro con arco, golpe con dos flechas, libro, el collar y

\footnotetext{
1 Pedagoga, Mestre em Educação. Atua na área da educação, principalmente arte, cultura e formação de professores. Coordenadora do Museu da Infância. E-mail: edinabaumer@gmail.com.

${ }^{2}$ Acadêmica do curso de Artes Visuais - Bacharelado da UNESC; Bolsista de Ação Educativa do Museu da Infância da UNESC.

${ }^{3}$ Acadêmica do curso de Artes Visuais - Licenciatura da UNESC; Bolsista de Ação Educativa do Museu da Infância da UNESC.
} 
la escultura de los animales salvajes; muñecas abayomis ', muñeca de trapo, libro y un muñeco negro de 1940. Estas colecciones de objetos proposicionalmente dialogados con diez acuarelas digitales, tamaño A1, artista Fabiano Vianna, de Curitiba, y una serie de fotografías que registran el Dr. Zilda Arns Neumann acciones de la Pastoral.

Palabras-clave: Extensión Universitaria; Museo de la Infancia; Alianza; Zilda Arns. 


\section{INTRODUÇÃO}

Este artigo tem por objetivo descrever uma experiência de extensão universitária promovida pelo Museu da Infância da UNESC, cuja finalidade, entre outras, consiste em:

[...] II - Organizar exposições temáticas para a visitação pública, visando à ampliação do repertório artístico-cultural, a construção da cultura de valorização da infância, da memória e da identidade, a constituição de uma cultura de visitação dos museus, de forma a efetivar ações que promovam a emancipação do sujeito/cidadão [...]. (UNESC, 2014, p. 2).

Nessa direção, o Museu da Infância tem organizado diversas exposições ao longo dos seus onze anos de existência, em núcleos espalhados pelo campus da Universidade do Extremo Sul Catarinense e também fora dele, estendendo-se até as escolas municipais e Centros de Referência e Assistência Social da cidade de Criciúma, e, mais, recentemente, estendendo-se até o município vizinho de Forquilhinha, estabelecendo uma parceria com a Associação de Amigos da Pastoral da Criança, com o intuito de homenagear a Dra. Zilda Arns, natural daquele município e reconhecida internacionalmente por seus trabalhos em favor das crianças.

A parceira foi de iniciativa da comunidade de Forquilhinha e teve acolhimento na universidade, primeiramente no âmbito do Museu da Infância e posteriormente na Unidade Acadêmica de Humanidades, Ciências e Educação e Pró-Reitoria de Pós-graduação, Pesquisa e Extensão e da UNESC. Este artigo de experiência registra todo o processo de estabelecimento da parceria e atesta que a UNESC cumpre seu papel de universidade comunitária quando reafirma seu " [...] compromisso com a produção de um saber socialmente construído e historicamente preservado nos seus diversos níveis voltados ao atendimento dos interesses da maioria da população [...]" (UNESC, 2015, p. 5).

Dessa forma, a estrutura apresenta os primeiros contatos, as primeiras proposições e seus desdobramentos, depois relata as duas exposições organizadas e mediadas pelo Museu da Infância na AAPAC, em Forquilhinha, finalizando com o registro da assinatura do Termo de parceria entre as partes, que oficializou todo o processo de parceria.

\section{CONSTRUINDO A PARCERIA}

No início do ano de 2015 recebemos o email de Ariane A. A. de Oliveira Salgado, que foi a primeira bolsista de ação educativa do Museu da Infância, no início de suas atividades, nos anos de 2005 e 2006. Na época, Ariane cursava a graduação em Letras na UNESC e relata que "o fato de ter iniciado esta trajetória em um museu dentro de uma universidade com certeza cooperou para que as vivências fossem pautadas por reflexão crítica, mas não há 
dúvida de que essa não é a realidade dos museus em geral" (SALGADO, 2016, p. 14-15). Talvez essa percepção tenha motivado Ariane, agora graduada em Letras (UNESC) e Mestre em Patrimônio e Museologia (UNIRIO), a enviar um email ao Museu da Infância, propondo um encontro para uma conversa onde pudéssemos alinhavar ações de assessoramento à criação de uma exposição no município de Forquilhinha - SC, em homenagem à Dra. Zilda Arns Neumann, fundadora da Pastoral da Criança, com um "[...] trabalho de mais de trinta anos dedicado às crianças de zero a seis anos [...]" (SALGADO, 2016, p. 16).

Nesse primeiro encontro com a coordenação do Museu da Infância, Ariane informou que trabalhava no Museu da Vida, em Curitiba-PR, uma "instituição inaugurada em dezembro de 2014 que tem como objetivo promover informação e reflexão através de exposições e ações educativas sobre saúde, nutrição, educação e cidadania no cuidado com a criança na família, bem como preservar a memória da missão da Dra. Zilda Arns Neumann" (SALGADO, 2016, p. 16). E explicou a intenção de organizar uma exposição permanente na cidade natal de Zilda Arns para que toda a população do município de Forquilhinha-SC e região tivesse a oportunidade de reconhecer cada vez mais a relevância de seu trabalho. Para Ariane Salgado (2015):

A cidade é cenário dos relatos das memórias de infância da médica, de modo que sua história e a de sua família se confundem com as origens da própria cidade. Nascida em 1934, Zilda Arns foi contemporânea ao início do desenvolvimento da localidade, tendo, por exemplo, estudado na segunda escola criada no local. ${ }^{4}$

Para os idealizadores da proposição - familiares da doutora e a ex-bolsista Ariane - o Museu da Infância poderia subsidiar a proposta de criação da exposição, convergindo para o que determinam as Políticas de Extensão da UNESC, na linha de extensão intitulada Patrimônio Cultural, Histórico, Natural e Imaterial, que entre outros aspectos, considera a “[...] organização, manutenção, ampliação e equipamento de museus, bibliotecas, centros culturais, arquivos e outras organizações culturais, coleções e acervos [...] valorização do patrimônio; memória, produção e difusão cultural [...]”" (UNESC, 2015, p. 25).

Com disposição para participar da ideia apresentada, a coordenação do Museu da Infância se propôs a elaborar o projeto de parceria, que sistematizou as ideias dentro do objetivo geral de estabelecer uma parceria entre o Museu da infância da UNESC e a AAPAC (Associação de Amigos da Pastoral da Criança de Forquilhinha-SC), para a organização de uma exposição permanente na Casa Mãe Helena, naquele município. E como objetivos específicos da equipe da universidade: assessorar a organização da exposição na Casa Mãe

\footnotetext{
4 Disponível em: https://www.pastoraldacrianca.org.br/museudavida/noticias/573-museudavidapastoraldacrianca-org-br-exposicao-sobre-dra-zilda.
} 
Helena; pesquisar a infância da Dra Zilda Arns, no que se refere aos brinquedos e brincadeiras daquela época, que ela possa ter brincado; criar e instalar um novo núcleo do Museu da Infância na Casa Mãe Helena contendo os brinquedos antigos, resultado das pesquisas; realizar ações educativas e mediações nas visitas agendadas; divulgar o trabalho de extensão universitária da UNESC por meio do Museu da Infância; e ampliar as possibilidades de visitação do público-alvo entre a exposição na Casa Mãe Helena e o Museu da Infância na UNESC.

\subsection{Concretizando a proposição}

Enquanto o projeto tramitava nos diversos âmbitos necessários para sua oficialização na universidade, um primeiro passo já se dava para a concretização da parceria: iniciamos a contribuição disponibilizando uma bolsista de ação educativa do Museu da Infância para participar do planejamento da montagem da primeira exposição e que ocorreria na casa Mãe Helena, em Forquilhinha, no mês de outubro do corrente ano. O primeiro encontro foi efetivado no dia 10 de setembro de 2015 entre a bolsista do Museu da Infância da Unesc e a Ariane (funcionária do Museu da Vida de Curitiba-PR) para proceder ao reconhecimento do local (Casa Mãe Helena / Forquilhinha-SC), analisando a distribuição do espaço para a exposição do acervo. Nesse dia foram revisitados e selecionados os objetos a serem expostos no espaço determinado e as atividades de organização foram finalizadas no dia 06 de outubro de 2015. Os objetos selecionados do acervo do Museu da Infância foram os dois biloques (ou bilboques) de 1990, uma mesa com cadeiras e um trem de madeira, em miniatura, um carrinho de madeira, um cavalinho de pau, pula-corda, cinco marias e a boneca alemã de 1895. 
Figura 1. Espaço expositivo na Casa Mãe Helena 2015.

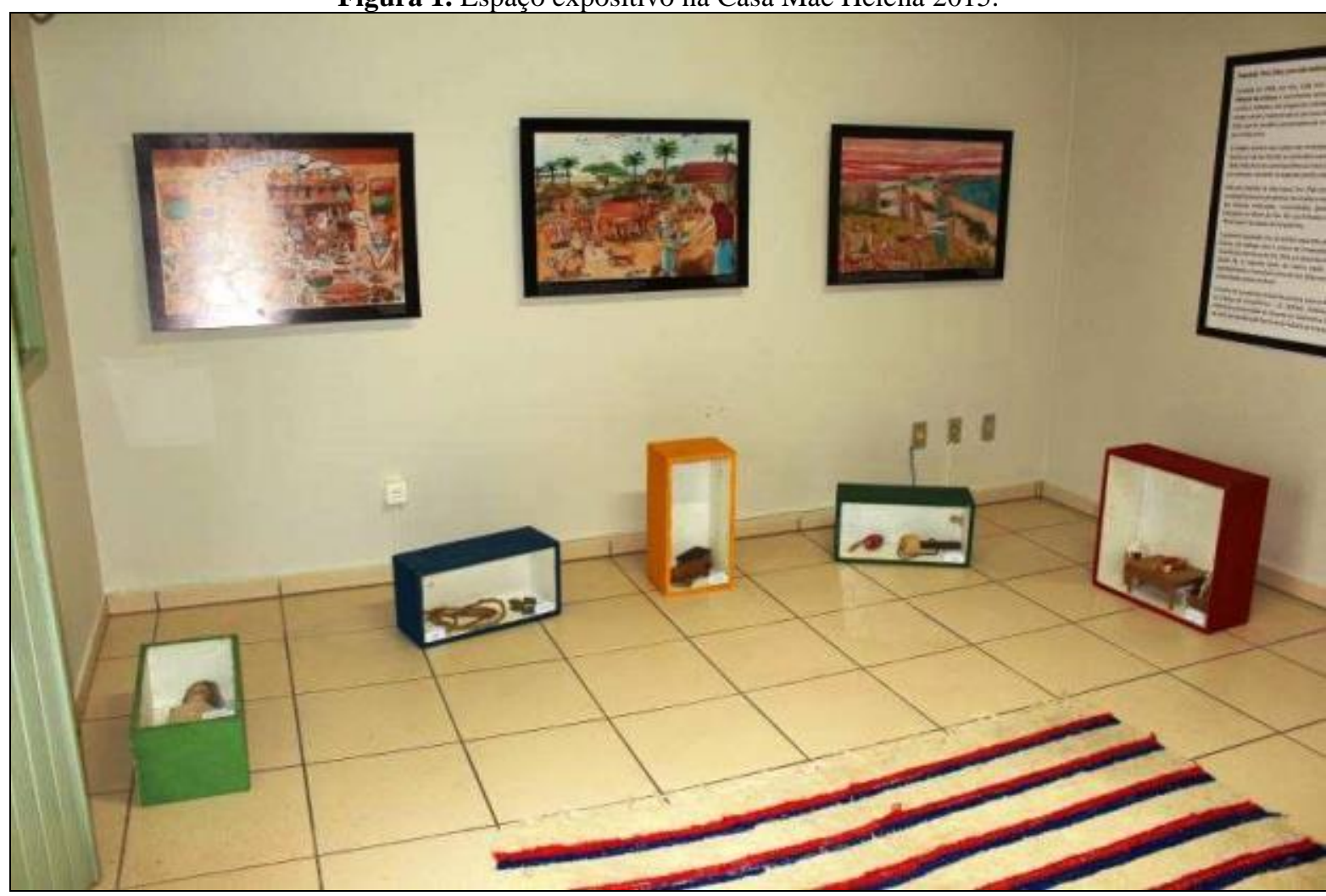

Fonte: https://www.forquilhinhanoticias.com.br/forquilhinha-conta-com-exposicao-sobre-doutora-zilda-arns/.

Esses brinquedos foram colocados nas vitrines expositoras pequenas - as primeiras que o Museu da Infância teve nos anos de sua fundação - e dialogaram proposicionalmente com as dez aquarelas digitais, tamanho A1, do artista Fabiano Vianna, de Curitiba, produções que não fazem parte do acervo do Museu da Infância, mas que agora pertencem à exposição permanente na Casa Mãe Helena. O artista curitibano confeccionou suas aquarelas com base nos relatos das memórias de infância da doutora, que são encontradas no livro Dra Zilda: Vida plena para todas as crianças, de 2014. A legenda de cada aquarela possui títulos como: Café da manhã, Férias na praia, Morro dos Conventos, A doença de pai Gabriel, Aprendendo a curar, Mãe Helena, Música e Tempos de guerra. Títulos que agregam citações de Zilda Arns Neumann, cheias de significados e de emoções da sua infância. Na obra Café da Manhã podemos ler a seguinte descrição:

Um ritual diário: o café da manhã era chamado de Frühstük, como se fosse um pequeno almoço; a família se reunia em volta de uma mesa grande. Rezávamos antes e depois de comer. Era mais que um café colonial, com muitos alimentos: [...] requeijão, pão de milho assado na brasa, leite, ovos fritos e cozidos, geleias, mel, carne-seca frita com cebola, acompanhada de pirão de farinha de mandioca (PASTORAL DA CRIANÇA, 2014, p. 37).

Dessa forma, a mesa e cadeiras de madeira, em miniatura, vêm para firmar a relação com o Frühstük; além disso o Museu da Infância confeccionou duas bonecas de pano para 
sentar-se à mesa e, ainda, com massa de modelar, produziu alimentos como pães, queijos, entre outros. O conjunto dos elementos expostos - as aquarelas, o acervo do Museu e as fotografias de Jader da Rocha que registram a figura da Dra. Zilda em ações da Pastoral da Criança - em sua totalidade nessa exposição contam e recontam histórias e memórias.

A exposição intitulada "Dra. Zilda: uma vida dedicada à infância" teve sua abertura no dia 10 de outubro, com a presença de autoridades do município e especialmente familiares da Dra. Zilda, como a secretária de Assistência Social Lilian Arns, uma das idealizadoras do projeto da exposição permanente. A exposição ficou aberta à visitação durante os três dias da Festa Heimatfest ${ }^{5}$ e a mediação cultural foi realizada pelas duas bolsistas de ação educativa do Museu da Infãncia e uma bolsista integrante do Projeto itinerante 'o Museu na escola'6. Pensando em oportunizar uma interação maior com o público visitante, preparamos caixas surpresas em MDF que possuem uma abertura na frente para colocar a mão e explorar o objeto em seu interior, tentando identificá-lo e relacioná-lo com o entorno ou com a exposição em si.

Ao elaborarmos o relatório dessa atividade foi possível constatar que a parceria entre instituições que pretendem agir na direção da preservação do patrimônio cultural - como o Museu da Infância da UNESC e a AAPAC (Associação de Amigos da Pastoral da Criança Forquilhinha-SC) fortaleceu a ampliação de repertório cultural e de valores indispensáveis para a vida humana porque sustentou-se

[...] na busca do resgate da narrativa, da experiência, da humanização, compreendendo que o novo se faz a partir do velho. Provocar esta relação é possibilitar uma forma outra de produção de sentido, de descobertas, de trocas, tanto para as crianças, quanto para os velhos. É uma nova forma de se escrever a História (LEITE, 2006, p. 10).

O projeto envolveu a comunidade do município e região, que teve a oportunidade de reconhecer e valorizar, cada vez mais, a relevância do trabalho da Dra Zilda Arns, ao visitar a exposição permanente na Casa Mãe Helena. O livro de assinaturas que registra a presença dos visitantes assinala a visita de 79 pessoas da cidade de Forquilhinha, 209 pessoas pertencentes a outros municípios de Santa Catarina, 12 pessoas de outros estados do país e 1 visitante do exterior (Califórnia - EUA). Temos ainda o registro de 27 assinaturas de visitantes que não

\footnotetext{
${ }^{5}$ Heimatfest / Festa das Origens é considerada uma das maiores festas do Sul de Santa Catarina. Ocorre na cidade de Forquilhinha há cada dois anos com o intuito de resgatar as raízes e valorizar os costumes dos colonizadores alemães, italianos, poloneses, portugueses, japoneses e afrodescendentes. Disponível em: http://gpm.fecam.org.br/forquilhinha/estruturaorganizacional/hotsite/index/codHotsite/3596.

${ }^{6}$ Projeto de extensão da UNESC desenvolvido nos anos de 2014 e 2015, com o objetivo de aproximar, sensibilizar e oportunizar às crianças das escolas Municipais de Criciúma um maior contato com o Museu da Infância.
} 
colocaram suas cidades de origem e 5 assinaturas as quais não conseguimos identificar o município, totalizando 333 visitantes.

A Casa Mãe Helena, localizada na Rua Alameda Felipe Arns, em frente à Praça dos Imigrantes Alemães, no Centro de Forquilhinha, recebeu esse nome em homenagem a mãe da doutora Zilda Arns que, juntamente com sua irmã Zélia, doou parte do terreno para a construção da casa, que foi inaugurada no dia 17 de abril de 2004 e que abriga a Pastoral da Criança em Forquilhinha ${ }^{7}$. Atende vinte e cinco municípios da Diocese de Criciúma e recebe periodicamente, grupos de agentes das pastorais e grupos diversos, que se alojam no estabelecimento para realizar estudos e encontros temáticos ou por ocasião de eventos específicos na cidade. Um desses eventos é o Seminário de Políticas Públicas para a Primeira Infância, que já teve três edições, reunindo

[...] Unicef, Pastoral da Criança, com apoio da Rede Nacional Primeira Infância, Rede Não Bata Eduque, Fundação Abrinq e Egem [...] conselheiros de Direitos da Criança e do Adolescente, Conselheiros Tutelares, Educadores, Socioeducadores, Orientadores Sociais, Pedagogos, Psicólogos, Assistentes Sociais, Promotores, Juízes, Advogados, Conselheiros de demais Políticas Públicas, Secretários Municipais, bem como demais atores do Sistema de Garantia de Direitos. ${ }^{8}$

Na última edição, datada de 30 e 31 de março de 2016, o objetivo foi promover o debate sobre as aprendizagens humanas para a primeira infância, considerando que essa é uma fase determinante da vida de todas as pessoas. Com o tema 'Um tributo à Zilda Arns', o evento incluiu em sua programação a exposição permanente instalada na Casa Mãe Helena, que foi reorganizada e mediada pelas bolsistas do Museu da Infância da UNESC.

Do acervo que já estava na exposição no ano anterior substituímos aquele jogo das cinco marias por outro similar e retiramos o cavalinho de pau; foram acrescentadas três vitrines expositoras grandes ao conjunto das vitrines pequenas que, para essa exposição, foram pintadas de branco, e um mini piano de madeira. Os novos objetos expostos se relacionam com a ditadura militar e períodos de guerra, como os livros alemães, disco de vinil e um cavalo; dois cestos indígenas, dois chocalhos, arco e flecha, sopro com duas flechas, livro, colar e escultura de animais silvestres.

\footnotetext{
${ }^{7}$ Informação disponível em: http://www.forquilhinha.sc.gov.br/turismo/item/detalhe/14469.
} 
Figura 2. Exposição Casa Mãe Helena 2016.

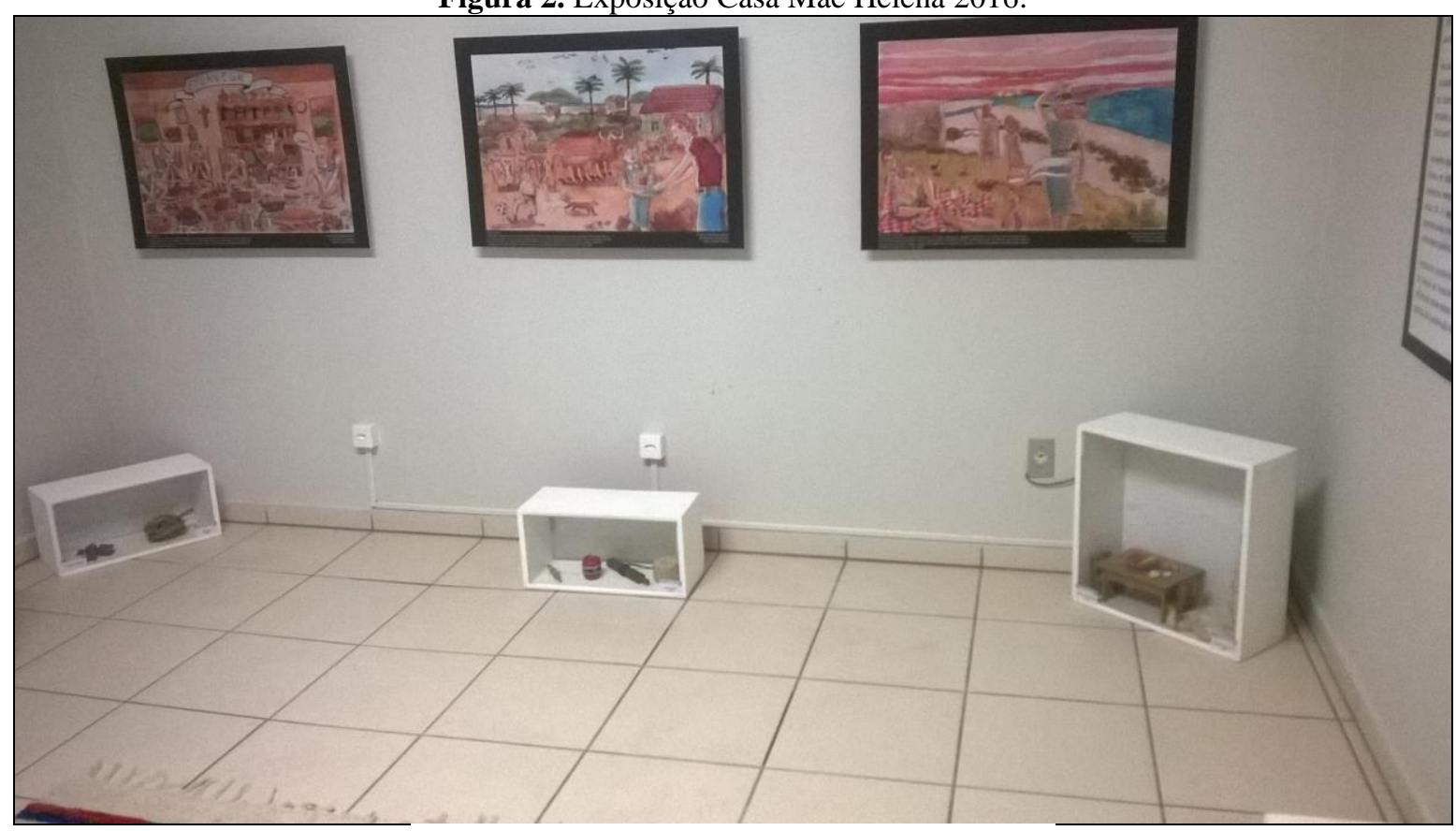

Fonte: Arquivo do Museu da Infância - UNESC.

Mais uma vez os objetos do acervo do Museu da Infância dialogam com o seu entorno, com por exemplo as fotografias: algumas delas retratam a doutora indo até as aldeias, registrando que Zilda Arns realizou trabalho em inúmeros lugares e comunidades, inclusive em aldeias e comunidades africanas. Nessa direção, uma das vitrines expositoras desse espaço contou com bonecas 'abayomis', boneca de pano, livro e uma boneca negra do Rio Grande do Sul de 1940.

Como elemento propositor para a interação, levamos para essa exposição o 'boliche do Museu da Infância', um brinquedo produzido com garrafas PET que trazia em cada garrafa uma imagem de algo relacionado à exposição, à vida da doutora Zilda Arns e ao Museu da Infância.

\footnotetext{
${ }^{8}$ Informação disponível em: http://turismo.sc.gov.br/evento/3o-seminario-nacional-de-politicas-publicas-para-aprimeira-infancia-um-tributo-a-zilda-arns/.
} 
Figura 3. Boliche do Museu da Infância.

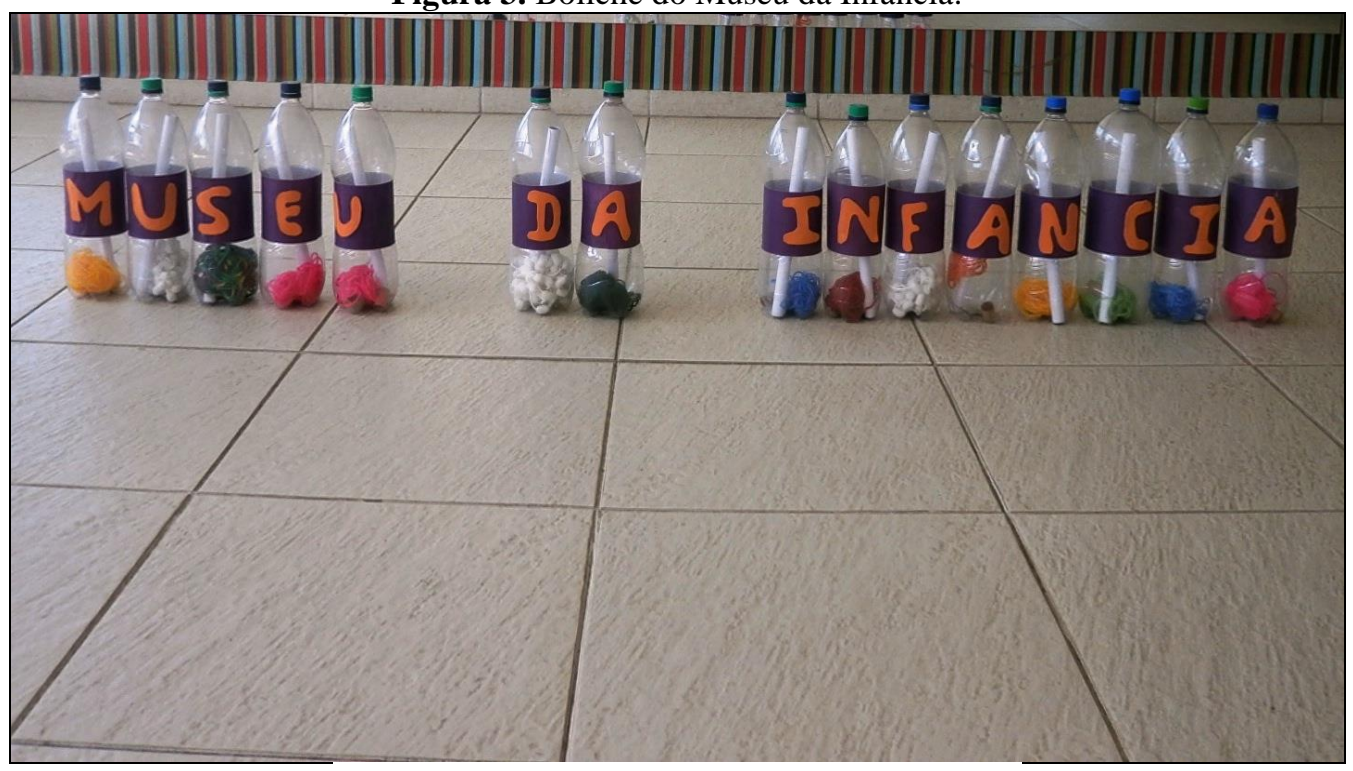

Fonte: Arquivo do Museu da Infância - UNESC.

$\mathrm{Na}$ hora do jogo, quem derruba uma das peças do boliche faz a mímica conforme a imagem do papel e o parceiro ou a parceira devem reconhecer do que se trata. Uma brincadeira simples mas que marca a importância de se permitir brincar, conhecer e aprender de forma lúdica.

Nessa exposição, o livro registrou 12 visitantes da cidade de Forquilhinha, 26 vindos de outros municípios do estado de Santa Catarina, 7 pessoas de outros estados do país e 1 pessoa do exterior (Itália); apenas 2 pessoas não colocaram endereço, totalizando como 48 o número do público visitante.

Dessa forma, antes mesmo da assinatura do Termo de Parceria entre o Museu da Infância e a AAPAC, duas exposições já haviam sido realizadas como ações de extensão importantes dentro das características de uma universidade comunitária seguindo a proposição de ampliar os espaços de atuação, conforme descreve o documento das Políticas de Extensão da UNESC (2015), ao relatar o histórico da extensão na instituição. Segundo esse documento, entre os anos de 2009 e 2012, “[...] as ações comunitárias da extensão universitária foram ampliadas com a efetiva participação de entidades parceiras, bem como o amplo envolvimento de estudantes e professores nos bairros e comunidades foram potencializadas [...]" (UNESC, 2015, p. 11).

A assinatura do Termo ocorreu na sala da Reitoria, no dia 14 de junho de 2016, com as presenças do reitor da UNESC, Gildo Volpato, a pró-reitora de Pós-Graduação, Pesquisa e Extensão, Luciane Ceretta, as representantes da Pastoral da Criança de Forquilhinha, Lilian 
Arns e a Irmã Marinez Gambim, a coordenadora do Museu da Infância, Édina Regina Baumer, e as bolsistas de ação educativa, Alice Meis e Sheila Brigido.

Figura 4. Assinatura do termo de convênio.

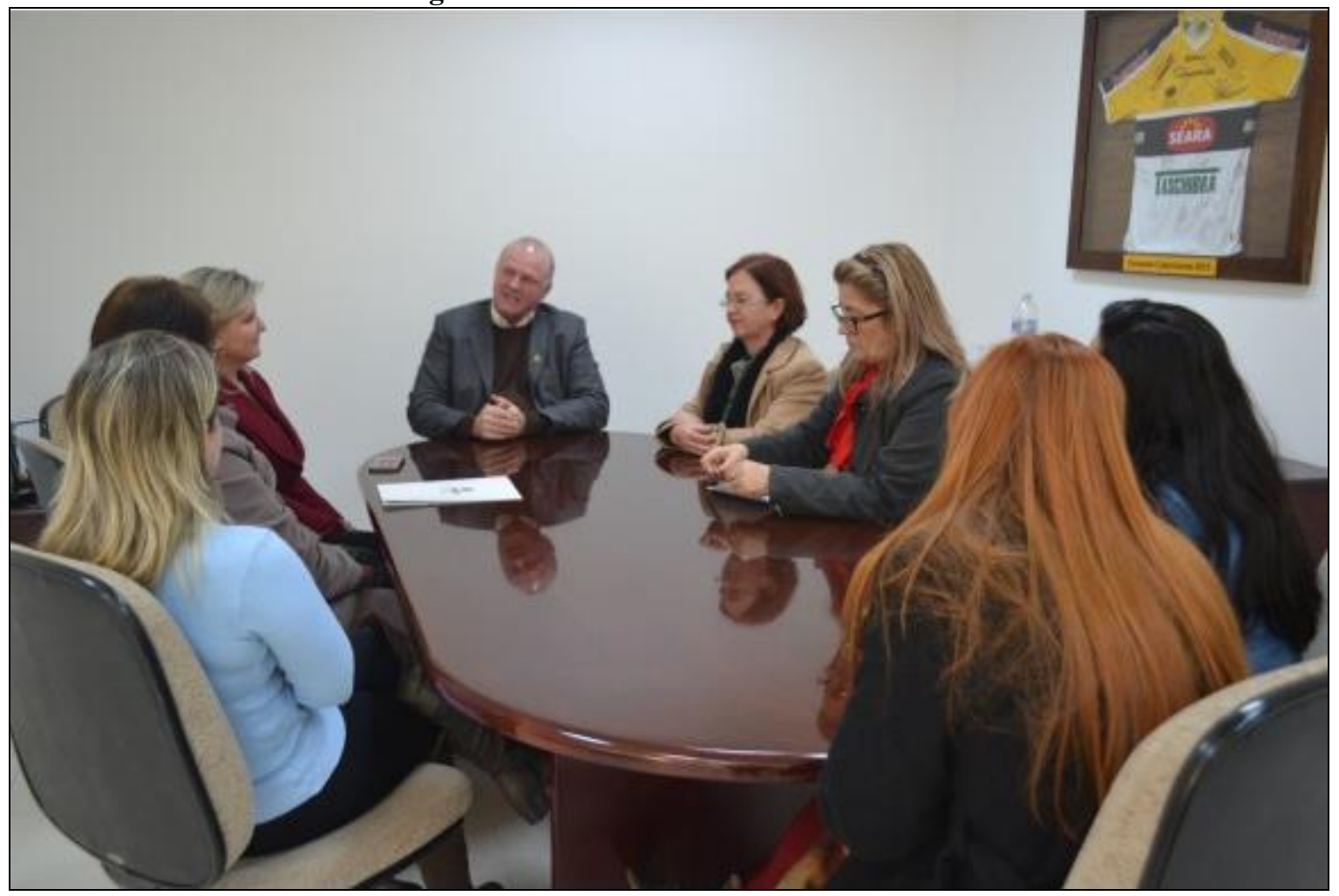

Fonte: http://www.unesc.net/portal/blog/ver/235/34765.

A parceria foi firmada com base no projeto elaborado pelo Museu da Infância e determinou que:

São obrigações da CONVENIADA: a) Oportunizar a criação de um núcleo do Museu da Infância na Casa Mãe Helena contendo brinquedos antigos e resultados de pesquisas; b) Viabilizar ações educativas e mediações nas visitas agendadas; c) Divulgar o trabalho de extensão universitária; d) Responsabilizar-se pelo material / acervo colocado em exposição o mantendo em bom estado de conservação o devolvendo quando solicitado ou em caso de rescisão do presente instrumento. São obrigações da UNESC: a) Assessorar a organização da exposição; b) Pesquisar a infância da Dra. Zilda Arns no que se refere aos brinquedos e brincadeiras da época e que possa ter brincado; c) Criar e instalar um novo núcleo do Museu da Infância na Casa Mãe Helena contendo brinquedos antigos e resultados de pesquisa; d) Realizar ações educativas; (UNESC, CONVÊNIO..., 2016, p. 2).

Nesse cenário, o Museu da Infância da UNESC sente sua responsabilidade e continua trabalhando para a concretização de seus objetivos que, entre outros, envolvem:

I - Pesquisar, valorizar, organizar, preservar, expor e comunicar sobre concepções de infâncias e seu acervo que é composto por produções das crianças, para crianças, e também sobre a infância; [...] II - Colaborar na formação e aperfeiçoamento de profissionais e docentes, do corpo técnico e funcional de museus, nos projetos de ação educativa das escolas, dando subsídios para pesquisadores da infância e para as políticas de educação e de acesso à cultura; IV - Manter intercâmbio com outras 
entidades congêneres visando atuação integrada com fins preservacionistas, e propiciar o aperfeiçoamento do corpo técnico e funcional. (UNESC, 2014, p. 2).

No entanto, vale ressaltar que o acervo exposto nos núcleos do Museu - seja no campus da UNESC ou em seus núcleos expositivos itinerantes ou no novo núcleo instalado na Casa Mãe Helena - representa “[...] histórias, vivências, objetos, materiais e até mesmo, ações da sociedade" (SILVA, 2015, p. 16), o que torna a ação educativa um momento rico de ressignificações e impulsiona a continuidade desse trabalho.

Assim, partindo da ideia de que um museu guarda objetos/imagens que foram especiais para as pessoas, ou para uma comunidade, sociedade ou época, isto é, seus tesouros, aquele que o contempla também aciona seus próprios tesouros, compostos por suas memórias, sonhos, histórias, imaginação e experiências anteriores (LEITE, 2012, p. 340).

A Universidade do Extremo Sul Catarinense - UNESC concedeu desde a sua formação quatros títulos honoríficos de Doutor Honoris Causa, o primeiro deles foi em 1998 a Dom Paulo Evaristo Arns e o segundo título de Doutor Honoris Causa foi concedido em 2002 para a irmã de Dom Paulo, Dra. Zilda Arns Neumman ${ }^{9}$ por suas contribuições e ações juntamente a Pastoral da Criança, que visam a redução da mortalidade infantil e a valorização dos direitos da criança.

Em uma dessas ações no Haiti, em 2010, Zilda Arns veio a falecer, mas seu legado de amor e dedicação pela infância sempre continuará entre nós. Enfim, Zilda é um tesouro da cidade de Forquilhinha, do estado de Santa Catarina e do Brasil.

\section{CONCLUSÃo}

Ao concluir este artigo de experiência, consideramos que foi um ganho realizar a parceria entre o Museu da Infância da UNESC e a Associação de Amigos da Pastoral da Criança, visto que o Museu sempre busca atender aos convites da comunidade em geral, para desenvolver ações culturais seja no campus da universidade ou nos diversos espaços das cidades ao seu entorno.

Com a oficialização da parceria, ressaltamos a importância da extensão universitária, divulgamos a função do Museu da Infância e parte do seu acervo artístico-cultural e ressignificamos o trabalho da Zilda Arns, que atuou com a infância, obtendo maior visibilidade com relação aos aspectos da saúde da criança. No entanto, suas proposições também levavam em conta a questão do brinquedo e do brincar na infância, como parte fundamental no desenvolvimento da pessoa, por isso acreditamos que atingimos o objetivo da

\footnotetext{
${ }^{9}$ Zilda Arns recebeu mais quatro títulos honoríficos, em outras universidades, além do título pela Universidade do Extremo Sul Catarinense - UNESC.
} 
parceria até o presente momento e pretendemos, por meio de pesquisa, aprofundar os estudos sobre esse aspecto - do brincar - na trajetória da Dra. Zilda.

A exposição do acervo na Casa Mãe Helena marcou a diversidade cultural em que a Dra. Zilda vivia e acreditava, o que nos leva a pensar que sua principal preocupação sempre foi com as 'pessoas', sejam elas de qual cultura, nacionalidade ou condições sociais se encontravam. Nesse sentido, vale promover ações de extensão universitária onde a comunidade local e regional possa se sentir contemplada ao perceber valorizada suas particularidades, sua história, suas memórias, numa relação de troca de saberes e entre saberes.

\section{REFERÊNCIAS}

LEITE, M. I. Museu: Espaço Impulsionador de Reconfigurações Identitárias Docentes. Scielo, Campinas, v. 32, n. 88, p. 335-350, set. 2012. Disponível em: <http://www.scielo.br/pdf/ccedes/v32n88/a06v32n88.pdf>. Acesso em: 28 set. 2016.

PASTORAL DA CRIANÇA. Dra Zilda: vida plena para todas as crianças. Curitiba: Museu da Vida, 2014.

SALGADO, A. A. A. de O. Educadores, formação e processos de mediação: crianças pequenas e arte contemporânea no museu. 2016. 103 f. Monografia (Graduação) Faculdade de Artes do Paraná, Universidade estadual do Paraná, Curitiba, 2016.

SILVA, G. K. Ação educativa em museus: registros e reflexões sobre a produção dos painéis dos direitos da criança no Museu da Infância. 2015. 63 f. Monografia (Graduação em Artes Visuais) - Universidade do Extremo Sul Catarinense, Criciúma, SC, 2015.

UNESC. Convênio que entre si celebram a... Procuradoria Jurídica da Universidade do Extremo Sul Catarinense, Criciúma-SC.

UNESC. Políticas de Extensão da Unesc. Resolução n. 12/2015. CONSU. Universidade do Extremo Sul Catarinense, Criciúma-SC. 40 p.

UNESC. Regulamenta o funcionamento do museu da infância. Resolução n. 01/2014. REITORIA. Universidade do Extremo Sul Catarinense, Criciúma-SC. 04 p. 